\title{
O Cabaleiro das Dúas Espadas e a recepción da materia de Bretaña na Península Ibérica
}

\author{
SANTIAGO GuTIÉRREZ GaRCÍA
}

Entre os múltiples aspectos suscitados polo estudio da literatura medieval que ata o de agora ficaron á espera dunha resposta satisfactoria está o da introducción da materia de Bretaña na Península Ibérica. Despois do traballo fundamental que a comezos de século publicara Entwistle ${ }^{1}$, outros estudiosos foron botando luz ó respecto ata completar un panorama máis axeitado sobre como debeu de se-lo proceso de transmisión da literatura artúrica ós reinos hispáni$\cos ^{2}$. Durante moito tempo o centro de atención estivo focalizado na cuestión das primeiras traduccións artúricas ás linguas vernáculas, derivándose unha longa polémica arredor de qué romance hispánico foi o primeiro en glosa-las aventuras do rei Artur e os seus cabaleiros ${ }^{3}$. Os achádegos de I. Castro parecen

1 W. J. ENTWISTLE, A lenda arturiana nas literaturas da Península lbérica, Imprensa Nacional, Lisboa, 1942.

2 M. R. LidA DE MALKIEL, «Arthurian Literature in Spain and Portugal», en R. S. Loomis, Arthurian Literature in the Middle Ages. A Collaborative History, Oxford University Press, Oxford, 1959, pp. 406-418; H. L. SHARRER, H. L. SHARRER, «The Acclimatization of the Lancelot-Grail Cycle in Spain and Portugal», en W. W. Kibler (ed.), The Lancelot-Grail Cycle: Text and Transformation, University of Texas Press, Austin, 1994, pp. 175-190. Para o estudio da literatura artúrica na Península Ibérica resulta de grande utilidadeo libro de H. L. SHARRER, $A$ Critical Bibliography of Hipanic Arthurian Material. I. Texts: the Prose Romance Cycles, Grant \& Cutler, Londres, 1977.

3 Vid. a este respecto, K. PIestch, Spanish Grail Fragment. El libro de Josep Abarimatia, La Estoria de Merlin. Lançarote, University of Chicago Press, Chicago, 1924-1925, t. I, p. XXII; Entwistle, $A$ lenda arturiane, pp. 6-24 e 120-127; M. RoDRIGUEs LAPA, $A$ 'Demanda do Santo Graal' . Prioridade do texto portugués, en Miscelânea de Lingua e Literatura Portuguêsa Medieval, Universidade de Coimbra, Coimbra, 1982; C. E. PICKFORD, «La priorité de la version portugaise de la Demanda do santo Graals, Bulletin Hispanique, LXIII (1961), pp. 211-216; F. BoGDANOw, «Old Portuguese seer em car teudo and the Priority of the Portuguese Demanda do Santo Graal», Romance Philology, XXVIII (1974), pp. 48-51 e «The Relationship of the Portuguese and Spanish Demandas to the Extant French Manuscripts of the Post-Vulgate Queste del Saint Graal», Bulletin of Hispanic Studies, LII (1975), pp. 13-31. 
resolve-lo asunto a favor do portugués, pois segundo este estudioso, as primeiras traduccións peninsulares serían obra dun crego lisboeta vinculado á corte de Afonso III o Bolonhês, que traballaría coas versións francesas do ciclo da PostVulgata que o monarca lusitano puido traer do seu exilio en Francia 4.

Outro asunto de grande interese, a data de introducción da materia bretona, recibiu un pulo decisivo coas investigacións levadas a cabo por D. Hook no eido da onomástica ${ }^{5}$. Os resultados dos seus traballos permite adianta-los primeiros testemuños artúricos en máis de medio século respecto ós datos fornecidos pola literatura. En efecto, durante moito tempo considerouse o ensenhament que o trobador Guiraut de Cabrera dirixiu ó xoglar Cabra como a máis antiga referencia peninsular sobre literatura artúrica ${ }^{6}$. Nesta composición menciónanse a Erec, Enide, Tristán, o rei Marco, entre otros personaxes xa daquela famosos nos reinos meridionais do Occidente europeo. As novas datas propostas por Hook veñen corroboradas pola interpretación, debida de S. Moralejo, dun relevo da Porta Francigena da catedral de Santiago de Compostela. Nel está tallado un guerreiro doente que navega nunha barca á deriva e que posiblemente represente a Tristán na embarcación que o ha levar a Irlanda para cura-la súa ferida tralo combate con Morholt.

Entre os elementos que axudaron a traza-lo proceso de transmisión da materia de Bretaña pola España dos séculos XII e XIII, desempeñaron un papel destacado as alusións que contén a poesía lírica galego-portuguesa. A importancia destas referencias foi xa comprendida por Carolina Michaelis, que lles adicou especial atención no seu estudio e edición do Cancioneiro da Ajuda? A pesar do seu escaso número, pouco máis dunha ducia, son especialmente relevantes para calibra-lo grao de penetración do ciclo artúrico entre os trobadores galego-portugueses, por canto sobrepasan con moito calquera outro tipo de referencias literarias reflectido nas cantigas desta escola poética. A súa variedade, polo demais, trae á luz cuestións moi variadas e define un panorama de influencias insospeitadamente variado. Entre este conxunto de alusións ${ }^{8}$, pasou

4 1. CASTRO, «Sobre a data da introdução na Península Ibérica do ciclo arturiano da Post-Vulgata», Boletim de Filologia, XXXVIII (1983), pp. 81-98.

5 D. HoOK, «Domnus Artux: Arthurian Nomenclature in 13th-c. Burgos», Romance Philology, XLIV (1990), pp. 162-164, The Earliest Arthurian Names in Spain and Portugal, Fontaine Notre Dame, St. Albans, 1991 e «Futher Early Arthurian Names from Spain», La Corónica, XXI, 2 (1992-1993), pp. 23-33 e «Esbozo de un catálogo cumulativo de los nombres artúricos peninsulares anteriores a 1300», Atalaya. Revue Française d'Études Médiévales Hispaniques, VII (1996), pp. 135-152.

6 M. Mila i Fontanals, De los trovadores en España, C.S.I.C. / Patronato Menédez Pelayo / Instituto Miguel de Cervantes, Barcelona, 1966, pp. 243-251.

7 C. MiChaÉlis de VASCONCElos, Cancioneiro da Ajuda, Imprensa Nacional - Casa da Moeda, Lisboa, 1990 (1.. ed. Halle, 1904), t. II, p. 508.

8 H. L. ShARRER, «La materia de Bretaña en la poesía gallego-portuguesa», en Actas del I Congreso de la Asociación Hispánica de Literatura Medieval. Santiago de Compostela, 2 al 6 de Diciembre de 1985, PPU, Barcelona, 1988, pp. 561-569; C. Alvar, «Poesía gallego-portuguesa y Materia de Bretaña: algunas hipótesis», en $O$ cantar dos trobadores. Actas del Congreso cele- 
desapercibida para moitos estudiosos a que contén un escarnio do que é autor Afonso X o Sabio:

Don Gonçalo, pois queredes ir daqui pera Sevilha, Por veerdes voss'amiga, e[u] nóno tenh'a maravilha:

Contar-vos-ei as jornadas légoa [e] légoa, milh[a] e milha.

$E$ ir podedes a Libria e torceredes já quanto, e depois ir a Alcalá se[n] pavor e se[n] espanto que vós ajades d'i perder a garnacha nen no manto.

E ua cousa sei eu de vós e tenho por mui gran brio, e poren vo-lo juro muit[o] a finas e a fio: que sempre avedes a morrer en invern'o[u] en estio.

Eu poren [de] vo-lo rogo e vo-lo dou en conselho que vós, entra[n]te a Sevilha, vos catedes no espelho e non dedes nemigalha por mercee de Joan Coelho.

Por que vos todos amassen sempre vós muito punhastes, böos talhos en Espanha metestes, pois i chegastes, e quen se convosco filhou, sempre vós d'el gaanhastes.

Sen esto, fostes cousido sempre muit' e mesurado, de todas cousas comprido e apost'e ben talhado, $e$ [e]nos feitos ardidos e muito aventurado.

$E$ pois que vossa fazenda teedes ben alumeada $e$ queredes ben amiga fremosa e ben talhada, non façades dela capa, ca non é cousa guisada.

$E$ pois que sodes aposto e fremoso cavaleiro, $g$ [u]ardade-vos de seerdes escatimoso ponteiro, ca dizen que baralhastes con [Don] Joan Coelheiro.

Con aquesto que avedes mui mais ca outro compristes; u quer que mäo metestes, guarecendo, en saistes; a quen quer que cometestes, sempre mal o escarnistes.

E non me tenhades por mal, se en vossas armas tango: que foi das duas [e]spadas que andavan en uu mango?, ca vos oi eu dizer:-Con estas pato ei e frango.

E ar oí-vos eu dizer que a quen quer que chegassen con esta vossa espada, que nunca se trabalhassen jamais de o guareceren, se o ben non agulhassen.

brado en Santiago de Compostela entre os días 26 e 29 de abril de 1993, Xunta de Galicia, Santiago de Compostela, 1993, pp. 31-51. 
E por esto [vos] chamamos nós "o das duas espadas», por que sempre as tragedes agudas e amoadas, con que fendedes as penas, dando grandes espadadas 9 .

As dificultades interpretativas, propias das cantigas de escarnio, vense neste caso aumentadas pola relación da devandita composición con outras dúas do trobador portugués Gonçal'Eanes do Vinhal, que así mesmo suscitaron lecturas moi diverxentes. Os acontecementos que están na orixe deste pequeno ciclo serían os amores entre o infante Don Enrique, irmán de Afonso X, e a súa madrasta Dona Juana de Ponthieu, que provocaron a ira do rei Sabio. Co gallo do escándalo suscitado por este asunto, Gonçal'Eanes compuxo dous escarnios de amigo: Amigas, eu oy dizer e Sey eu, donas, que deytad'é d'aqui 10, que C. Alvarll interpretou coma sendos ataques por parte do trobador portugués cara 6 infante e que $R$. Lapa e A. Vínez ${ }^{12}$ consideraron intentos de intermediación que o trobador dirixiu 6 monarca para acada-lo perdón de Don Enrique.

Sexa como for, o certo é que o escarnio afonsí acusa unha actitude equívoca de Gonçal'Eanes nas súas relacións con Don Enrique e co propio rei. En efecto, como vénse sinalando dende hai tempo polos críticos que se teñen achegado a este texto, a clave interpretativa da composición sería a posible traizón do trobador -o que Lapa denomina «atitude bifronte»-respecto 6 seu señor, o monarca castelán 13 . Sabido é que a inimizade entre Afonso e Enrique baseábase en asuntos máis trascendentais, que afectaban á política do reino. A pugna entre ambos irmáns polos dereitos sucesorios de Fernando III ou mesmo a rebelión de 1255 por parte de Enrique convertían en sospeitoso o tratamento cordial que con este segundo mantiña Gonçal'Eanes 14 . O portugués, de tódolos xeitos, gozaba dunha posición favorable na corte de Afonso, de aí, en parte, que o monarca lle dirixa o escarnio a maneira de aviso. Neste sentido, non estará de

9 M. Rodrigues LAPA, Cantigas d' escarnho e de mal dizer dos cancioneiros medievais galego-portugueses, Galaxia, Vigo, 1970 (2.. ed.). pp. $42-43$.

10 A. VIÑez SANCHEz, Don Gonçal' Eanes do Vinhal: reconstrucción histórico-biográfica y edición crítica de su obra. Tesis Doctoral, Universidad de Cádiz, 1993, p. $530-538$ e 662-676.

"I C. Alvar, «Poesía y política en la corte alfonsí», Cuadernos Hispanoamericanos, CDX (1984), p. 13.29. Li Chevalier as deus espees, ed. de W. FOERSTER, Halle, 1877. Vid. A. MichA, "Miscellaneous French Romances in Verse», en R. S. Loomis, Arthurian Literature in the Middle Ages. A Collaborative History, Oxford University Press, Oxford, 1959, p. 379-380.

12 Rodrigues LaPA, Cantigas d'escarnho, p. 42-43; VÍNEZ SÁNChEZ, Don Gonçal'Eanes, p. 235.

13 Rodrigues Lapa, Cantigas d'escarnho, p. 65; Hernández SERna, «A propósito de «Don Gonçalo, pois queredes ir daqui pera Sevilha” de Alfonso X el Sabio (Vida y obra de Don Gonçal'Eannes do Vinhal. I)», Estudios Románicos, I, 1978, p. 211; VíNez SÁNCHEZ, Don Gonçal' Eanes, p. 236; F. MAGAN ABELlEIRA e X. X. RON FERNÁNDEZ, "Algunhas consideracións ecd6ticas e hermenéuticas sobre a cantiga «Don Gonçalo, pois queredes ir daqui pera Sevilha" (B 466) de Alfonso X o Sabio", Revista de poética medieval, Ill (1999), pp. 134-135.

14 Para as relacións entre Afonso X e Don Enrique, vid. VIÑEZ SÁnCHEZ, Don Gonçal' Eanes, pp. 220-232. (y a ser posible, A. BALlesteros BERETTA, Alfonso X el Sabio, Barcelona, 1963. 15 ViñzZ SÁNCHEZ, Don Gonçal' Eanes, p. 33-38 e 236-244. 
máis lembrar que o trobador compuxo os seus escarnios de amigo entre finais de 1255 e comezos de 1256 e que Afonso X comporía a cantiga que agora nos ocupa un pouco máis tarde, non despois de 1257, cando o portugués recibiu do monarca o señorío de Aguilar de la Frontera ${ }^{15}$. As tres composicións, daquela, dataríanse nun momento en que a rebelión do infante estaba aínda moi recente.

A posible traizón de Gonçal'Eanes aparece condensada nas tres derradeiras estrofas do escarnio afonsí, onde se fai referencia ás armas do trobador portugués. Segundo declara o rei Sabio, a actitude equívoca do seu protexido faino merecedor do epíteto de "o das dúas espadas". Tal e como está empregado, o sintagma en cuestión ten todo o aspecto de ser unha expresión dabondo coñecida polo público da cantiga, o que fai pensar que, ademais dun envío á traizón de Gonçal'Eanes, agoche unha referencia á marxe das circunstancias glosadas na composición. Neste sentido, todo apunta cara a unha referencia literaria, moi posiblemente, como veremos a continuación, relacionada coa literatura artúrica.

Gonçal'Eanes, o Don Gonçalo ó que vai dirixida a cantiga, é coñecido por uns misteriosos cantares de Cornoalha, que, segundo el mesmo declara en Maestre, todo' lus vossos cantares ${ }^{16}$, formaban parte do seu repertorio. A exacta natureza destas composicións é asunto debatido que, debido á vaguedade da alusión, está aínda hoxe sen resolver. Os famosos cantares de Cornoalha tan pronto designarían, segundo opina C. Alvar ${ }^{17}$, simples pezas de temática cortés, sen unha vinculación directa coa materia bretona, como lais artúricos 6 xeito das composicións que encabezan o cancioneiro da Biblioteca Nacional e que reciben a denominación de lais de Bretanha18. De ser certa esta segunda hipótese, reafirmaría un presunto coñecemento do ciclo do rei Artur por parte de Gonçal'Eanes; mais, á marxe desta filiación concreta, e tal e como reflicten as alusión contidas na producción profana do rei poeta e nas Cantigas de Santa María a familiaridade da corte afonsí con este tipo de narracións está fóra de toda dúbida. A única mención que aparece na lírica profana -o nome de Tristán como exemplo do sufrimento amoroso en Ben ssabia eu, mha senhor ${ }^{19}$ - non deixa de ser un lugar común consagrado dende había moitos anos, pero, pola súa banda, o cancioneiro mariano contén tres mencións de grande interese 20 : na cantiga 35 dise que Bruto e Artur foron os poboadores da cidade de Dover,

16 lbid., pp. 647-661.

17 Alvar, «Poesía gallego-portuguesa», pp. 42-45. Vid. así mesmo J.-M. D'Heur, «Gonçal'Eanes do VinHaL, ses 'chansons de Cornoaille' et le respect de l'art poétique (Arturiana 2)», en G. COLÓN e R. KOPP (eds.), Mélanges de langues et de littérature romanes offerts d Carl Theodor Gossen, Frank Verlag / Marche Romane, Berna / Liexa, 1976, pp. 185-194.

18 Michaellis de VASCONCElos, Ajuda, t. I, pp. 629-630.

19 Cantigas d'Amor dos Trovadores Galego-Portugueses, ed. de J. J. Nunes, Centro do Livro Brasileiro, Lisboa, 1972, pp. 52-54.

20 Afonso X o SABio, Cantigas de Santa María, ed. de W. Mettmann, Xerais, Vigo, 1981, t. I, pp. 202-206 e 408-410 e t. II, pp. 398-403. 
na 108 desenvólvese unha historia na que Merlín propicia a conversión dunha comunidade de xudeus e na 419 menciónase a desaparición de Artur, de acordo coa formulación do motivo da 'esperanza bretona', que negaba a morte do mítico monarta ${ }^{21}$.

Ey vista dos datos anteriores, non é ilóxico pensar que tralo apelativo adia Gonçal'Eanes, no que se lle chama 'o das dúas espadas', se agoche un envío a algún episodio da materia de Bretaña que, volvemos repetir, é o ciclo literario que máis veces se asoma ós versos da escola lírica galego-portuguesa. Neste sentido, a vinculación coa literatura artúrica non é novedosa. Unha referencia 6 respecto atópase, por exemplo, no manual de Literatura gallega de A. Tarrío 22 , onde, sen embargo non se explicitan nin a cantiga na que aparece a alusión nin, claro está, o personaxe que merecía tal alcume. Magán e Ron retoman a cuestión intentando establece-la fonte da que puido obter Afonso X o devandito epíteto23. Agora ben, a cuestión clave é determinar qué personaxe da literatura artúrica era coñecido polo sobrenome de 'o das dúas espadas'.

No conxunto da literatura artúrica hai ata catro cabaleiros que levan o devandito alcume. $O$ máis célebre é Palamedes, o cabaleiro sarraceno tamén chamado 'o Descoñecido' ou 'o Cabaleiro da Besta Ladrador'. É este un personaxe tardío que aparece por primeira vez a mediados do século XIII no Tristan en prose e que foi retomado polas obras en prosa serodias -Queste dou Saint Graal do ciclo da Post-Vulgata, Guiron le Courtois, Les Prophecies de Merlin, Compilación de Rusticiano de Pisa 24-. Palamedes é un dos grandes rivais de Tristán, co que compite en van polo amor de Iseo. Mais, contra o que puidera parecer, é unha figura positiva, que finalmente establece co sobriño de Marco unha sólida amizade, se converte 6 cristianismo, pasa a formar parte da Mesa Redonda e se atopa entre os elixidos para contempla-los misterios do Santo Graal. O motivo das dúas espadas aparece nun episodio ó comezo do Tristan en prose 25 . Durante un torneo convocado pola Doncela das Landas, asiste un cabaleiro descoñecido que leva dúas

21 Para o estudio destas referencias, vid. M. MARTINS, «Merlim numa cantiga de Santa Maria», Estudos de Cultura Medieval, III (1983), pp. 45-49; SHARRER, «La materia de Bretaña», pp. 563-564; AlVAR, «Poesía gallego-portuguesa», pp. 34-36; D. E. CARPENTER, «A Sorcerer Defends the Virgin: MERLIN in the Cantigas de Santa Maria», Bulletin of the Cantigueiros de Santa Maria, V (Spring 1993), pp. 5-24.

22 A. TARrio VARElA, Literatura gallega, en Historia crítica de la Literatura Hispánica, t. XXVIII, Taurus, Madrid, 1988, p. 32 e Literatura galega. Aportacións a unha historia crítica, Xerais, Vigo, 1994, p. 59.

23 MAGAN E RON, «Algunhas consideracións», pp. 136-138.

24 G. D. WEST, An Index of Proper Names in French Arthurian Prose Romances, University of Toronto Press, Toronto / Buffalo / Londres, 1978, pp. 242-243; C. Ayjar, El rey Arturo y su mundo. Diccionario de mitología artúrica, Alianza Editorial, Madrid, 1991, pp. 325-326. Para a análise deste personaxe nas versións hispánicas dos romans artúricos vid. P. MICHON, «Palaméde dans les romans arthuriens de la Péninsule Ibérique», Travaux de littérature, IX (1996), pp. 7-19.

25 E. LOSETH, Le roman en prose de Tristan. Le roman de Palamede et la compilation de Rusticien de Pise. Analyse critique d'après les manuscrits de Paris, Slatkine, Xenebra, 1974, S 29. 30.

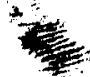


espadas. Explícase que quen ousaba facer tal cousa era porque estaba disposto a enfrontarse con dous adversarios ó mesmo tempo, de igual xeito que se ese cabaleiro era vencido por algún dos integrantes da Mesa Redonda, estaría obrigado a non empuñalas durante un ano. Segundo o esperado, Palamedes ten un comportamento heroico no torneo e como premio consegue a man da Doncela, que, sen embargo, rexeita. Con todo, a aventura que máis sona lle deu foi a da Beste Glatissant -a Besta Ladrador dos textos hispánicos-á que perseguía incansablemente e da que chegou a pinta-la imaxe no seu escudo.

O segundo personaxe é moito menos coñecido. Trátase de Samaliel (ou Gamaliel), fillo do príncipe Frolle, que así mesmo aparece no Tristan en prose e na Queste da Post-Vulgata. Segundo a primeira destas obras 26 , Samaliel acudira ó reino de Logres para vingar a seu pai, morto a mans de Artur ${ }^{27}$. Alí foi armado cabaleiro por Galaad e deu en levar dúas espadas: a que recibiu o día que ingresou na orde de cabalería e a do seu pai, a quen quería igualar en valentía e honor. Un día que atopa o senescal Keu, cóntalle que tal costume implicaba un grande risco, por canto obrigaba, chegado o caso, a combater con dous cabaleiros a un tempo. Gamaliel, que non coñecía o costume, promete levalas sempre por amor a seu pai e a Galaad. $O$ carácter positivo do personaxe revélase no episodio en que atopa a Artur dormido e desiste de toma-la vinganza que tanto desexaba. En sinal do seu perdón, déixalle a espada de seu pai e toma a do rei.

Un novo cabaleiro das dúas espadas é Meriadeuc28, que dá nome o roman en verso titulado $L i$ Chevalier aus Deus Espees, obra datada na primeira metade do século XIII29. Meriadeuc, fillo dun cabaleiro chamado Bleheri, descoñecía a súa ascendencia ata que un día chegou casualmente ó castelo da Dama do Lago dos Xemeos. Esta, que resulta ser súa nai, revélalle o nome de seu pai e as circunstancias en que morreu. Meriadeuc emprende daquela a vinganza de Bleheri. $O$ alcume que o caracteriza gáñao durante unha estancia na corte de Artur, ó descingui-lo cinto encantado que levaba unha doncela, Lore de Caradigan, e

26 Le roman de Tristan en prose, coord. de Ph. MÉnARD, t. IX, La fin des aventures de Tristan et de Galaad, ed. de L-Harf-Lancner, Droz, Xenebra, 1997, cap. 92, pp. 211 - cap. 107, p. 235. LOSETH, Le roman en prose de Tristan, $S$ 527-557. O relato do Tristan en prose correspóndese, a grandes trazos, co da Demanda do Santo Graal portuguesa (A Demanda do Santo Graal, ed. de I. Freire-Nunes, Imprensa Nacional - Casa da Moeda, Lisboa, 1995, pp. 386-399).

27 O personaxe de Flolle remonta ó Frollon da Historia Regum Britanniae de Geoffrey de Monmouth. Nesta obra era o tribuno romano que gobernaba a Galia e que, durante a conquista de París por parte do exército bretón, foi morto por Artur en combate singular ante as murallas da cidade. No Tristan en prose, segue como gobernador de París, pero agora é un príncipe de orixe alemana e pasou a ser un xigante (Geoffrey de Monmouth, Historia Regum Britanniae, en E. FARAL, La légende arthurienne. Études et documents, Honoré Champion, París, 1993, t. III, cap. 155, p. 239-241; Tristan en prose, t. IX, cap. 28, p. 112). Vid. Alvar, El rey Arturo, p. 174.

28 ALvAR, El rey Arturo, pp. 65-66.

29 Li Chevalier as deus espees, ed. de W. Foerster, Halle, 1877. Vid. A. MiCHA «Miscellaneous French Romances in Verse», en R. S. LoomIs, Arthurian Literature in the Middle Ages. A Collaborative History, Oxford University Press, Oxford, 1959, p. 379-380. 
ficar coa espada que colgaba del. Unha vez que vence e mata a Brien de la Gastine, o asasino de seu pai, Meriadeuc regresa á corte artúrica e casa con Lore.

Moi semellante $\delta$ relato anterior é o que protagoniza o cuarto cabaleiro das dúas espadas, chamado Balaain o Salvaxe. Este personaxe irrompe na materia bretona na Suite du Merlin da Post-Vulgata e reaparece noutros romans da metade do século XIII, como a Queste da Post-Vulgata e Guiron le Courtois. Segundo o relato da Suite du Merlin ${ }^{30}$, Balaain, cabaleiro pobre de Northumberland, deuse a coñecer na corte de Artur 6 consegui-la espada que unha doncela levaba nun cinto encantado e que ningún cabaleiro de Logres conseguira descinguir. Como sinal do seu triunfo, queda coa espada e dende entón «l'apelerent tut communement le Chevalier as .II. Espees, e fu puis par tut conus par cel non»31. Sen embargo, ela advírtelle que a nova arma será a causa da súa ruína. Ese mesmo día, Artur expúlsao da corte por matar na súa presencia a outra doncela á que acusara de asesina-lo seu irmán. Pero Balaain está disposto a recupera-lo favor do monarca, polo que decide prestarlle un servicio que lle permita volver á corte. Coa axuda de seu irmán Balaan e de Merlín capturan ó rei Rion, que combatía contra o reino de Logres, e deste modo o das Dúas Espadas acada o perdon de Artur.

Pero as desgracias que lle profetizara a doncela non tardan en chegar. Baalain parte en busca dun cabaleiro invisible que mataba os seus adversarios a traizón. O cabaleiro resulta ser Garlan, fillo do rei Pellehan, quen custodiaba no seu castelo o Santo Graal e a lanza de Longinos. Baalain mata a Garlan e loita con Pellehan. No medio do combate, fire coa lanza a Pellehan, o castelo derrúbase e comezan os encantamentos do Santo Graal. Merlín advírtelle a Baalain que deu o Golpe Doloroso e que pola súa culpa o reino de Listenois ficará desolado durante vintedous anos e será coñecido como a Terre Gaste. Tempo despois, o das Dúas Espadas chega a un castelo no que rixe o costume de que todo forasteiro debe loitar co señor do lugar. Baalain acepta e emprende un combate terrible contra o cabaleiro descoñecido. Cando ámbolos dous adversarios non eran quen de continuar a causa das feridas, Baalain recoñece no seu rival a Balaan. Os dous morren na liza e Merlín constrúe unha tumba que sirva de lembranza ó sucedido.

$\mathrm{Na}$ análise que acabamos de trazar, o costume das dúas espadas atopa unha dobre explicación: ou ben o cabaleiro lévaas en lembranza de alguén moi querido -como fan Samaliel e Meriadeuc- ou ben como premio por teren superado unha proba -como sucede con Balaain e o mesmo Meriadeuc-. De todas formas, as analoxías entre os catro personaxes permite establecer sendas parellas, segundo o esquema narrativo que protagonizan. Tanto Palamedes como Gamaliel son cabaleiros estranxeiros que se dan a coñecer por un costume tan insólito como arriscado. Tal vez non sexa casualidade que ámbolos dous aparezan na

30 La suite du roman de Merlin, ed. de G. RoussineaU, Droz, Xenebra, 1996, cap. 94, p. 67 - cap. 240, p. 195.

31 lbíd., cap. 104, p. 75. 
mesma obra, o Tristan en prose, e que o seu comportamento mereza comentarios moi semellantes entre os demais cabaleiros. As similitudes entre Meriadeuc e Baalain son aínda máis evidentes, xa que un e outro protagonizan unha proba idéntica: a de descinguir dun cinto máxico unha espada que adoptarán como segunda arma. De feito, a débeda que o relato da Suite du Merlin ten co Chevalier as Deus Espees foi posta de manifesto en varias ocasions ${ }^{32}$.

Polo que se pode apreciar, se Afonso X se inspiraba nunha figura da materia de Bretaña para dirixi-lo coñecido epíteto a Gonçal'Eanes, tivo que ser dun destes catro personaxes. Agora ben, resulta evidente que todos eles presentan unha diferencia fundamental que dificulta a filiación: en calquera caso, as dúas espadas representan un signo de valentía e nunca de comportamento ambiguo. Certo é que nun primeiro momento tanto Palamedes como Samaliel representan funcións negativas, xa que o primeiro é sarraceno e rival de Tristán e o segundo acude a Logres para matar a Artur. Con todo, e tal e como puidemos comprobar páxinas máis arriba, o seu carácter valeroso e nobre non tarda en saír á luz. Meriadeuc, pola súa banda é en todo momento un personaxe positivo, mesmo cando ten que enfrontarse a Galván, pola morte de seu pai. A vinganza de Meriadeuc non se dirixirá, finalmente contra o sobriño do rei, senón contra o verdadeiro culpable, Brien de la Gastine.

Quen con diferencia desenvolve un papel máis equívoco é Balaain. A súa valentía tropeza contra unha serie de infortunios que o levan a da-lo Golpe Doloroso ou a matar a seu propio irmán. Función ambigua a deste Cabaleiro das Dúas Espadas, non tanto polo seu carácter coma polas consecuencias que as súas accións acarrean para o futuro do reino de Logres. A súa figura parece erixirse en paradigma do tráxico destino que ameaza ós personaxes do ciclo da Post-Vulgata e que define a traxectoria do roiaume aventureux ${ }^{33}$. A relación con Artur é sintomática desta posición equívoca, pois nela altérnan períodos de amizade e enfrontamento. De tódolos xeitos, a lealdade de Balaain queda fóra de toda dúbida, habida conta o empeño que pon en recupera-lo favor do rei e os servicios que lle presta incluso despois de caer en desgracia.

A pesar da distancia existente, a comparación entre a cantiga afonsí e o relato artúrico ofrece puntos de contacto como para sospeitar que é Balaain o Cabaleiro das Dúas Espadas 6 que se refería Afonso $\mathrm{X}$ na súa cantiga. Tanto Balaain como Gonçal'Eanes manteñen unha posición privilexiada nunha corte real. Ademais, como no caso do cabaleiro artúrico, o trobador portugués pon en

32 Micha, «Miscellaneous French Romances in Verse», p. 380.

3.3 Bogdanow, «The Suite du Merlin and the Post-Vulgate Roman du Graal», en Loomis, Arthurian Literature in the Middle Ages, p. $334 \mathrm{e}$ The Romance of the Grail. A Study of the Structure and Genesis of a Thirteenth-Century Arthurian Romance, Manchester University Press, Manchester, 1966, pp. 206-220; MiCHA, «L'Estoire de Merlin», en Grundriss der romanische Literaturen des Mittelalters, vol. IV/1, Le roman jusqu'd la fin du XIIIe siècle, Karl WiNTER VeRLAG, Heidelberg, 1978, p. 597; R. LATHUILLERE, «Le Roman du Graal postérieur à la Vulgate (Cycle du Pseudo-Robert de Boron)", en idem, ibidem, pp. 621-622; Roussineau, Là Suite, pp. IX-XL. 
perigo o favor conseguido á beira dun monarca co seu comportamento equivocado. Non deixa de ser sintomático, en fin, que tanto Balaain coma Gonçal'Eanes procedan dun reino viciño -Northumberland e Portugal- 6 da corte onde atopan acollida. De todas formas esta última semellanza non é dabondo significativa pois na materia bretona son numerosos os cabaleiros destacados que proceden terras alleas a Logres (Palamedes, Lanzarote, Bohort, Tristán...).

Un elemento máis a ter en conta nesta análise, e que resulta ser fundamental, é a ironía empregada no xénero de escarnio. Baixo este punto de vista, a comparación entre un cabaleiro nobre e desgraciado como Balaain deixaría máis en evidencia a actitude de Gonçal'Eanes, que, pola contra amósase indigno a pesar de terlle favorecido a fortuna. Esta clave interpretativa permite que a mención ás súas dúas espadas gañe en riqueza de matices que van máis aló da simple acusación de traizón. Afonso X parece recordarlle $\delta$ seu vasalo servicios que noutrora lle valeron a estimación na corte e que lle permitiron consegui-lo alcume xa coñecido, que, como a literatura artúrica demostraba, era sinónimo de valor cabaleiresco. Hai que recordar, a este respecto, que Baalain se consagrou como o mellor cabaleiro da corte de Artur ó arricar do cinto encantado a súa segunda espada ${ }^{34}$. E, se ben Gonçal'Eanes podía ter merecido o sobrenome polas súas cualidades guerreiras, o certo é que logo faise merecedor del manter unha dobre lealdade.

A este cambio de actitude podería referirse o verso 29: «que foi das duas [e]spadas que andavan en uu mango?», no que debería entenderse que noutrora poñía toda a forza da súa dobre espada 6 servicio dun só señor, cousa que, como reflicte a interrogación retórica, xa non o fai. Deste modo, o alcume de o das Dúas Espadas viralle agora por traelas «agudas e amoadas», ou o que é o mesmo, pola súa facilidade para cambiar de lealdades. A nova segunda espada referirase a don Enrique que, como no acaecido a Balaain, pode se-la causa da súa ruína. Polo tanto, se Gonçal'Eanes é Balaain, Afonso asume o papel de Artur, que, como sucedía na Suite du Merlin, espera un xesto do seu vasalo que rectifique os erros cometidos. Tal vez sexan algo máis que unha simple coincidencia as palabras que o monarca bretón lle dirixe 6 cabaleiro de Northumberland cando, cheo de carraxe, o expulsa da corte: «Tes estoit la maniere et la coustume de mon ostel, que vous avés enfrainte et depechie premierement par vostre orgueil. Si vous di bien que se vous estiés mes freres, si vous repentirés vous de che fait» 35 .

A posible identificación de Balaain o Salvaxe como o misterioso cabaleiro das Dúas Espadas á que se refire Afonso $X$ reviste unhas consecuencias que van máis aló da simple interpretación dunha cantiga e que afectan a todo o pro-

34 E a doncela que levaba a espada a que declara a smperioridade de Balaain: «Sire chevaliers, vous m'avés delivree et si i avés moult grant hounour conquist, car il est prouvee chose et aperte par ceste oevre que vous estes li mieudres chevaliers de chaiens.» (Suite du Merlin, cap. 96, p. 69).

35 Suite du Merlin, cap. 101, p. 73. 
ceso de recepción da materia bretona na Península Ibérica. En efecto a conocencia por parte do rei Sabio dun personaxe como Balaain implica a circulación por terras castelás do ciclo da Post-Vulgata (así mesmo denominado Roman du Graal). Lémbrese ó respecto que moi posiblemente a entrada do devandito ciclo no ámbito hispánico produciríase dende Portugal, vinculada á figura de Afonso III o Bolonhês ${ }^{36}$. E sería precisamente dende o occidente peninsular que estes textos se transmitirían a Castela 37 . O significativo do caso é a rapidez coa que o Roman du Graal traspasou as fronteiras portuguesas e se aclimatou no reino viciño, pois téñase en conta que Afonso III volve do exilio en 1245. Neste sentido, a mención ó Cabaleiro das Dúas Espadas é contemporánea á cantiga de Martim Soares Ua donzela que jaz preto d' aqui ${ }^{38}$, que contiña a que J.-M. d'Heur consideraba a máis antiga alusión artúrica contida na lírica galego-portuguesa ${ }^{39}$. Cuestión máis difícil de determinar é se o texo no que se baseou Afonso X se trataba dunha versión francesa ou dunha traducción, xa que a vaguedade da alusión non permite aventurar suposicións de ningún tipo. Neste aspecto, de todas formas, habería que ter en conta que a Post-Vulgata verqueríase do francés ó portugués por esas mesmas datas, pode que algún ano antes. Unha marxe cronolóxica tan estreita obriga a considerar outras posibilidades, entre elas, a de que algunha versión francesa puidese circular pola corte afonsí independentemente dos textos chegados a Portugal. Tal vez sexa bo recordar que o da recepción da materia artúrica na Península é un proceso que se documenta dende cen anos antes que os primeiros testemuños dun labor de traducción e que, nese sentido, é máis amplo e, se cadra, ata certo punto independente. Esta hipótese atoparía certo apoio a disparidade de fontes propostas para as diferentes referencias artúricas que aparecen nas composicions do monarca castelán.

Sexa como for, a mención ó Cabaleiro das Dúas Espadas sumada ás outras alusións artúricas incluídas na obra poética de Afonso X, de tal maneira que, polo seu número e a súa riqueza, configuran un panorama axeitado sobre a

36 Os testemuños do Roman du Graal conservados en lingua portuguesa son a adaptación da Estoire dou Saint Graal coñecida como Livro de Jose de Arimateia e o fragmento da Suite du Merlin, mentres que en castelán só se conserva o Livro de José de Arimatea (Lida de Malkiel, «Arthurian Literature», p. 409; A.-J. SOBERANAS, «La versión galaïco-portugaise de la Suite du Merlin», Vox Romanica, XXXVIII (1979), pp. 174-193). Para o papel desenvolvido polo Bolonhês, vid. supra, nota 4.

37 DE FEITO, Sharrer divide a Península Ibérica en tres grandes bloques á hora de explica-la difusión da materia de Bretaña: Galicia e Portugal, Castela e a Coroa de Aragón. Os textos da Post-Vulgata penetrarian na Península dende Portugal, onde se farían as primeiras traduccións, e dende aí pasarían a Castela (Sharrer, «The Acclimatization», p. 176).

38 V. Bertolucci Pizzorusso, «Le poesie di Martin Soares», Studi Medievali, X (1962), pp. $137-140$.

39 O protagonista desa composición recibía o apelativo de don Caralhote, nome burlesco de connotacións sexuais construído a partir do de Lanzarote. A fonte de Martin Soares serfa o Livre de Lancelot du Lac do ciclo do Lancelot-Graal ou da Vulgata (J.-M. d'Heur, «De Caradoc à Caralhote. Sur une pièce obscure de Martin Soares et son origine française presumée (Arthurienne I)», Marche Romane, XXIII - XIV (1973-1974), pp. 251-264). 
aceptación que as ficcións artúricas deberon ter na corte do rei trobador. Polo demais, a cronoloxía demostra unha recepción moi rápida de obras compostas a penas quince anos antes ${ }^{40}$, o que, daría unha idea da vitalidade da corte afonsí, que dcse xeito se configuraría coma un centro privilexiado de intercambios culturais.

4 O ciclo da Post-Vulgata comporíase entre os anos 1230 e 1240 (Bogdanow, «The Suite du Merlin», p. 335). 